\title{
Una mirada a las Organizaciones Solidarias activas en la Provincia de Guanentá Departamento de Santander Colombia
}

\section{A look at the Solidarity Organizations active in the Province of Guanentá Department of Santander Colombia}

Um olhar sobre as Organizações de Solidariedade que atuam na Província de Guanentá, Departamento de Santander Colombia

\section{Nohora Corzo-Gutiérrez ${ }^{1}$ \\ Uriel Sarmiento-Blanco ${ }^{2}$ Miguel Arturo Fajardo ${ }^{3}$}

Recibido: 15 de octubre de 2019

Aprobado: 15 de agosto de 2020

Publicado: 30 de septiembre de 2020

Cómo citar este artículo:

Corzo-Gutiérrez, N., Sarmiento-Blanco, U. y Fajardo, M.A. (2020). Una mirada a las Organizaciones Solidarias activas en la Provincia de Guanentá Departamento de Santander Colombia. Cooperativismo \& Desarrollo, 28(118), 1-29. doi: https://doi.org/10.16925/2382-4220.2020.03.01

Artículo de investigación. https://doi.org/10.16925/2382-4220.2020.03.01

1 Fundación Universitaria de San Gil-UNISANGIL, San Gil, Colombia. Km 2 vía San GilCharala. San Gil, Colombia.

Correo electrónico: ncorzo@unisangil.edu.co

ORCID: https://orcid.org/0000-0003-4267-9456

2 Fundación Universitaria de San Gil-UNISANGIL, San Gil, Colombia. Km 2 vía San GilCharala. San Gil, Colombia.

Correo electrónico: usarmiento@unisangil.edu.co ORCID: https://orcid.org/0000-0002-9874-714X

3 Fundación Universitaria de San Gil-UNISANGIL, San Gil, Colombia. Km 2 vía San GilCharala. San Gil, Colombia.

Correo electrónico: mfajardo@unisangil.edu.co ORCID: https://orcid.org/0000-0002-6592-7427 


\section{Resumen}

La economía solidaria ha evolucionado durante más de 40 años, a tal grado que algunos investigadores ven a las provincias del sur de Santander como un escenario del Modelo Cooperativista, una gran alternativa de desarrollo para las regiones. Por lo anterior, el objetivo general este estudio fue la caracterización de las Organizaciones Solidarias (os) activas en la provincia de Guanentá. En primer lugar, se identificaron las organizaciones solidarias existentes, posteriormente, se realizó un mapeo de dichas entidades y, finalmente, se identificaron algunas experiencias solidarias significativas presentes en la región. Para la investigación, se utilizó como metodología un enfoque mixto (cuantitativo y cualitativo), de carácter descriptivo-exploratorio y de corte transversal. Las técnicas utilizadas fueron la encuesta y la entrevista, el instrumento utilizado fue el cuestionario. Cabe mencionar que la encuesta se aplicó a 399 os y la entrevista a 11 os identificadas como experiencias significativas. Los hallazgos encontrados servirán de fuente de información para las instituciones interesadas en fortalecer el desarrollo de la economía solidaria en los municipios. Asimismo, el artículo resalta las características del capital social de las organizaciones solidarias, especialmente, su compromiso y su acción en la transformación social.

Palabras clave: Caracterización; Organizaciones Solidarias; Desarrollo Regional; Territorio Solidario; Economía Solidaria.

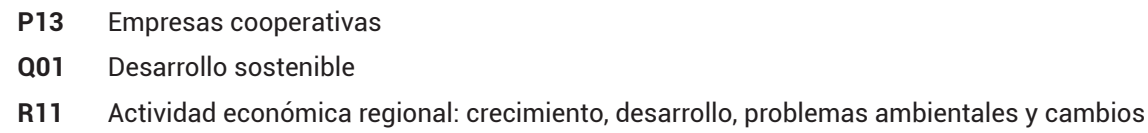

\section{Abstract}

The solidarity economy has evolved for more than 40 years, to such an extent that some researchers see the southern provinces of Santander as a setting for the Cooperative Model, a great development alternative for the regions. Therefore, the general objective of this study was the characterization of the Solidarity Organizations (OS) active in the province of Guanentá. In the first place, the existing solidarity organizations were identified, subsequently, a mapping of said entities was carried out and, finally, some significant solidarity experiences present in the region were identified. For the research, a mixed approach (quantitative and qualitative), descriptive-exploratory and cross-sectional, was used as a methodology. The techniques used were the survey and the interview, the instrument used was the questionnaire. It is worth mentioning that the survey was applied to 399 OSs and the interview to 11 OSs identified as significant experiences. The findings found will serve as a source of information for institutions interested in strengthening the development of the solidarity economy in the municipalities. Likewise, the article highlights the characteristics of the social capital of solidarity organizations, especially their commitment and action in social transformation.

Keywords: Characterization; Solidarity Organizations; Regional Development; Solidarity Territory; Solidarity Economy.

P13 Cooperative companies

Q01 Sustainable development

R11 Regional economic activity: growth, development, environmental problems and changes

\section{Resumo}

A economia solidária evoluiu há mais de 40 anos, a ponto de alguns pesquisadores enxergarem as províncias do Santander como cenário do Modelo Cooperativo, uma grande alternativa de desenvolvimento para as regiões. Anteriormente, o objetivo geral deste estudo era caracterizar as Organizações Solidárias (OS) atuantes 
na província de Guanentá. Em primeiro lugar, foram identificadas as organizações de solidariedade existentes, posteriormente foi feito um mapeamento dessas entidades e, por último, foram identificadas algumas experiências de solidariedade significativas presentes na região. Para a pesquisa, utilizou-se como metodologia uma abordagem mista (quantitativa e qualitativa), descritivo-exploratória e transversal. As técnicas utilizadas na entrevista e na entrevista, o instrumento utilizado foi o questionário. Vale ressaltar que a pesquisa foi aplicada a 399 SOs e a entrevista a 11 SOs identificados como experiências significativas. Os achados encontrados servirão de fonte de informação para instituições interessadas em fortalecer o desenvolvimento da economia solidária nos municípios. Da mesma forma, o artigo destaca as características do capital social das organizações solidárias, especialmente seu compromisso e ação na transformação social.

Palavras-chave: Caracterização; Organizações solidárias; Desenvolvimento Regional; Território de Solidariedade; Economia solidária.

Empresas cooperativas P13

Q01 Desenvolvimento Sustentável

R11 Atividade econômica regional: crescimento, desenvolvimento, problemas ambientais e mudanças

\section{Introducción}

En los últimos años se ha venido abriendo paso el término de "territorio solidario", reconocido como tal por la presencia significativa de organizaciones de economía solidaria que inciden en el desarrollo local (Fajardo, 2011). Según datos del Programa de las Naciones Unidas para el Desarrollo (PNUD) citado por Pabón (2011), Santander es hoy líder en la lucha contra la pobreza extrema con el puntaje más alto entre todos los departamentos y mantiene, desde 2009, el primer lugar en avances en Desarrollo Humano (que mide calidad de vida, vivienda y educación) con un crecimiento del $4.4 \%$, cifras que no pueden ser ajenas al importante aporte que el sector de la economía solidaria ha realizado. Cooperativas como Coomuldesa, Ecofibras, Cohilados, Coopmujer, Resander, instituciones educativas como Instituto Coomuldesa y la Fundación Universitaria de San Gil-UNISANGIL, entre muchas otras, invierten su trabajo y su experiencia para que este liderazgo nacional sea una realidad.

El tema se hace más relevante basado en la cultura solidaria que se abre paso en las provincias del sur de Santander. Según Fajardo (2011):

en los últimos años los gobernantes, investigadores y líderes sociales, en distintos escenarios han reconocido el desarrollo especial que ha tenido el cooperativismo y otras formas de solidaridad en las provincias del sur de Santander. Indudablemente, también hay un auto-reconocimiento de los logros alcanzados por las organizaciones de economía solidaria en los últimos 50 años. Por eso se puede afirmar que en las provincias del sur 
de Santander se ha avanzado en la construcción de una cultura solidaria. Poco a poco la población ha reconocido en la solidaridad el mejor camino para el mejoramiento de sus condiciones de vida. (p. 25)

De igual forma, la economía solidaria ha evolucionado durante más de 40 años, a tal grado, que el mundo ve al departamento de Santander y, especialmente, las Provincias de Guanentá, Comunera y Veleña como un escenario del Modelo Cooperativista definido y basado en los principios solidarios, cabe decir, que falta mucho por hacer, pero que el camino está cimentado y, por ello, se debe trabajar de manera conjunta entre todas las organizaciones solidarias, el Estado y las instituciones privadas para poder fortalecer más las empresas de economía solidaria y el impacto social que ellas traen consigo.

En este sentido, se hizo indispensable caracterizar las organizaciones solidarias activas de la Provincia de Guanentá, escenarios de actuación de un sin número de Organizaciones Sociales que, según datos de la Cámara Comercio-Seccional San Gil, 2016, en la provincia de Guanentá existen 566 organizaciones solidarias clasificadas de la siguiente manera: 28 Cooperativas de las cuales nueve son de ahorro y crédito, seis especializadas en ahorro y crédito, dos especializadas sin sección de ahorro, dos multiactivas sin ahorro y crédito, una cooperativa de trabajo asociado, dos instituciones auxiliares cooperativas, y seis enfocadas a las actividades de: transporte, agropecuarias, producción, entre otras; 78 fundaciones: 367 asociaciones, 84 corporaciones, una organización de voluntariado; dos fondos de empleados, cuatro asociaciones de vivienda y dos Federaciones. Estas cifras revelan la cantidad de empresas de economía solidaria que hacen presencia en la región y que han propiciado el desarrollo y crecimiento en las diferentes comunidades locales.

Sumado a lo anterior, actualmente no se cuenta con un sistema de información que permita identificar y caracterizar las organizaciones solidarias del territorio. Esta situación justificó la realización de un estudio de identificación y caracterización de las Organizaciones Solidarias Activas en la provincia de Guanentá, además de realizar un mapeo de dichas entidades e identificar las experiencias significativas y/o emprendimientos solidarios; asimismo, dentro de la investigación, se resaltan las características del capital social de las organizaciones solidarias, su compromiso y acción en la transformación social.

Los hallazgos servirán de fuente de información para las instituciones interesadas en fortalecer el desarrollo de la economía solidaria en los municipios. De hecho, los recientes acuerdos de paz firmados entre el Gobierno Nacional y las FARC-EP 
establecen que la economía solidaria es una de las estrategias fundamentales para la consolidación de la paz en el país.

Cabe destacar que a esta investigación le antecedieron: el Proyecto Territorio Solidario realizado por UNISANGIL, COOMULDESA y DANSOCIAL (2011); la Guía para el mapeo y relevamiento de la economía popular solidaria en Latinoamérica y Caribe (Coraggio, Arancibia y Deux, 2009); el Mapeamiento de las Organizaciones Solidarias de Bucaramanga (UCC, 2015) y el Proyecto red UNICOSOL, que lidera una macroinvestigación con diferentes universidades de la cual hace parte la Fundación Universitaria de San Gil, como encargada de la investigación de las organizaciones solidarias en la provincia de Guanentá.

\section{Métodología}

La investigación tomó como metodología el enfoque mixto (cuantitativo y cualitativo), cuyo tipo de diseño fue no experimental, de corte transversal y de carácter descriptivo, toda vez que su pretensión fue no manipular variables, sino observar los hechos tal cual sucedieron, además, la de recolectar información en un solo momento en el tiempo. La investigación tomó como población objeto de estudio a 566 empresas de economía solidaria de la provincia de Guanentá, Santander, según datos suministrados por la Cámara de Comercio Seccional San Gil, teniendo en cuenta que el trabajo se realizó con la totalidad de los elementos que compone la población, no se determinaron, ni desarrollaron cálculos muestrales. Por lo tanto, se hizo de manera censual.

La técnica utilizada fue la encuesta y el tipo de instrumento el cuestionario, los cuales iban dirigidos a los representantes legales de las organizaciones solidarias de los municipios que conforman la Provincia de Guanentá-Santander, donde se recolectó información pertinente a los objetivos planteados en la investigación. Cabe señalar que realmente se encuestaron 399 Organizaciones Solidarias, debido a que los representantes legales de las otras organizaciones no tenían la disponibilidad de tiempo para diligenciar el cuestionario, o en su defecto las os ya no estaban en funcionamiento.

Igualmente, se utilizó la entrevista para recolectar información de las experiencias significativas de algunas os, para este caso, se lograron obtener datos de nueve experiencias significativas o emprendimientos solidarios exitosos, las cuales fueron: Asociación de mujeres de pro desarrollo rural, Asociación de mujeres líderes del municipio de Curití, Asociación de suscriptores de acueducto rural "el Hobo", Asociación de Mujeres Cabeza de Hogar y Población Vulnerable de Aratoca, Asociación de jóvenes y productores rurales de cincelada (AJOPRUC)- corregimiento de Coromoro, 
Asociación y Suscriptores del Acueducto Rural Las Alegrías, Cooperativa de Ahorro y Crédito Barichara LTDA., Corporación de la Recuperación Comunera del Lienzo (CORPOLIENZO) y la Fundación Reserva Moral del Municipio de San Gil. Finalmente, se realizó el tratamiento de la información, utilizando el software Google Drive, que permitió la acumulación y tabulación de datos, base para el análisis de la información. Posteriormente, se generaron las conclusiones y recomendaciones del estudio.

\section{'Caracterizar' como forma de entender el tejido social de las Organizaciones Solidarias en los territorios.}

La Real Academia define caracterizar como "determinar los atributos peculiares de alguien o de algo, de modo que claramente se distinga de los demás". Puede referirse a personajes, tipografías, páginas web, empresas, productos, entre otros (LEXICOON, 2016). Asimismo, The Free Dictionary (2016) dice que caracterizar es: distinguir o diferenciar un rasgo a una persona o cosa de las demás. Igualmente, manifiesta, que es "presentar o describir una cosa con sus rasgos_característicos de manera que resulte inconfundible".

En este sentido, se podría decir que caracterizar es la identificación de aqueIlos atributos, rasgos, factores, propiedades, condiciones, particularidades, ya sea de una persona, de una comunidad, de una empresa, de un fenómeno, de un territorio, entre otros, que están presentes en un lugar específico y en un tiempo determinado. Asimismo, dentro de la determinación de las características se tiene en cuenta también el ámbito: social, económico, cultural, político, ambiental, tecnológico etc., que forman parte del contexto al cual se desea tomar determinadas particularidades; cabe mencionar que se tuvieron en cuenta algunos aspectos generales de los municipios que conforman la Provincia de Guanentá, con el propósito de comprender, en la medida de lo posible, el ámbito en que las os tienen su incidencia o participación.

En este orden de ideas, se tuvo en cuenta algunos elementos que pudieran dar indicios de las características propias de las os presentes en el territorio, dichos elementos serían los siguientes: la identificación de cada una de las os, su forma jurídica, el número de sedes que tiene la organización, el ámbito sociodemográfico (rural o urbano), tipo de organización de integración a la que pertenece como redes, movimientos, federaciones, asociaciones, entre otras, asimismo, conocer a qué tipo de actividad se dedican, el año en que comenzó actividades, número de asociados, número de personas beneficiadas, número de empleados, dificultades, fortalezas de la entidad y de los asociados, entre otros aspectos, que servirán para conocer de la manera más concreta posible cuántas y cuáles organizaciones están presentes en la 
Provincia de Guanentá, de igual forma saber cómo desde su accionar han mejorado la calidad de vida de las colectividades más vulnerables y entender cómo las empresas de economía solidaria han contribuido al desarrollo y crecimiento de la región.

\section{Resultados}

\section{Características de las Empresas de Economía Solidaria}

En la actualidad, la economía solidaria en Colombia es vista como un sector de la economía, pero sobre todo como un sistema que incluye una diversidad de actores que se relacionan y buscan el desarrollo integral de un colectivo. Es así que se aprecia el grado de importancia que han tomado los diferentes tipos de Organizaciones Sociales y Solidarias en el país. En este sentido, la Ley 454 de 1998 define las características de las empresas de economía solidaria, a continuación, se hará mención de las más importantes:

1. Tener como orientador de su acción los principios y fines establecidos en la Ley 454 de 1998.

2. Garantizar la igualdad de derechos y obligaciones de sus miembros, independientemente de sus aportes.

3. Los aportes sociales deben estar establecidos en sus estatutos, y todos los asociados han de aportar un monto mínimo no reductible; y las reservas sociales de la organización no se pueden repartir en caso de liquidación.

4. Ejercer una actividad socioeconómica que busque satisfacer las necesidades de sus asociados.

5. Ser una organización sin ánimo de lucro y que realice acciones orientadas a la solidaridad, de servicio comunitario o social.

6. Las organizaciones de economía solidaria deben destinar sus excedentes a la prestación de servicios de carácter social, y al crecimiento de sus reservas y fondos.

De igual forma, se tiene en cuenta dentro de la caracterización: los principios solidarios consignados en el artículo 4 de la ley 454 de 1998 y los valores solidarios relacionados naturalmente con los principios de las organizaciones solidarias.

Es importante destacar la autogestión como elemento fundamental en las organizaciones solidarias, este término es definido por Mothé (2009) como "un proyecto de organización democrática que privilegia la democracia directa" (p. 10); esto 
significa que se constituye en un sistema en que voluntariamente, sin remuneración y sin recurrir a intermediarios, los ciudadanos debaten todas las cuestiones importantes, a través de asambleas. La autogestión está representada en la autonomía de la gestión del emprendimiento, cooperativa, asociación, fondo de empleados y cualquiera que sea la forma de organización solidaria. De igual manera, en la ley se encuentran definidos los fines de las OES, dispuestas en el artículo 5 de Ley 454 del 1998.

En los enunciados anteriores, se aprecian las características de las OES, basadas en la Ley 454 del 1998; y sumado a lo expuesto, según la Unidad Administrativa Especial de Organizaciones Solidarias clasifica a las empresas de economía solidaria de la siguiente manera: las Organizaciones Solidarias de Desarrollo (OSD) y las Organizaciones Solidarias. En primer lugar, las OSD son aquellas que emplean recursos privados o gubernamentales para prestar servicios a la sociedad. Son ellas las fundaciones, corporaciones y asociaciones, juntas de acción comunal y grupos de voluntariado. En segundo lugar, se tienen las organizaciones solidarias las cuales son: las pre cooperativas, cooperativas, instituciones auxiliares de la economía solidaria, fondos de empleados, asociaciones mutualistas, empresas solidarias de salud, empresas comunitarias, organizaciones de segundo y tercer grado, empresas de servicios cooperativos y cooperativas de trabajo asociado, las cuales, desarrollan actividades de producción de bienes o servicios, y son dinamizadores del desarrollo en los territorios mediante la articulación de diferentes dimensiones o ejes: el económico, lo social, lo político, lo cultural, tecnológico, entre otros.

Por otra parte, están las entidades de apoyo al sector de la economía solidaria, que son las empresas estatales, privadas y otras de origen mixto. Estas funcionan como un sistema en el que la Unidad Administrativa Especial de Organizaciones Solidarias (USEOS), FOGACOOP, SUPERSOLIDARIA, CONES, FONES, el Ministerio de Trabajo y otras entidades del Estado se relacionan para promover, orientar y coordinar los procesos de la economía solidaria en el país.

Como se puede observar, hay un sinnúmero de tipos de osD y organizaciones solidarias como tal, cada una con determinadas características, que las hacen ser particulares y que, además, su funcionamiento depende también del contexto en que ejercen su actividad. Pero es de recalcar, que todos los tipos de empresas de economía solidaria están basadas en el marco de la ley 454 de 1998, lo cual, implica que las empresas de este sector buscan desde su accionar, la trasformación de las colectividades y el mejoramiento de la calidad de los asociados y de la comunidad en general. 


\section{Mapeamiento como fortaleza e integración de las Empresas de Economía Solidaria.}

Para esta investigación se tomaron algunos elementos del enfoque teórico y metodológico, presentada en la Guía para el mapeo y relevamiento de la economía popular solidaria en Latinoamérica y Caribe de Coraggio, Arancibia y Deux (2009), con el propósito de replicar experiencias de mapeamiento realizadas en América Latina y el Caribe, desde un enfoque similar que, en el futuro, le permita al grupo de investigación participante, planear acciones y realizar propuestas sobre los resultados. Cabe mencionar que los datos construidos a partir del mapeamiento de economía solidaria constituyen la base del Sistema Nacional de Información en Economía Solidaria (SIES), cuyos objetivos se definen como:

1. Construir una base nacional de información sobre Economía Solidaria.

2. Fortalecer e integrar los emprendimientos de Economía Solidaria a través de registros, redes, catálogos de productos.

3. Favorecer la visibilidad de la Economía Solidaria, fortaleciendo los procesos organizativos, de apoyo y adhesión de la sociedad.

4. Apoyar procesos públicos de reconocimiento y certificación de las iniciativas de Economía Solidaria.

5. Apoyar los procesos de formulación de políticas y la elaboración de un marco jurídico para la Economía Solidaria.

Como se puede apreciar, mapear se concibe como la descripción de un proceso a partir de la identificación y cuantificación de personas, empresas, fenómenos, entre otros aspectos presentes en un lugar determinado, y que permite, como lo menciona Coraggio (2009), la construcción de una base de datos, que debe contener información pertinente y confiable para una adecuada gestión, así como el fortalecimiento, articulación e integración de las diferentes Organizaciones Solidarias, tanto a nivel regional, departamental, nacional e internacional. Del mismo modo, se busca favorecer la visibilidad de las mismas, el apoyo en las políticas públicas, y la elaboración del marco jurídico, que posibilite a dichas entidades tener unas normas y leyes enmarcadas dentro de la jurisprudencia del gobierno nacional, y partir de allí poder tener unas bases sólidas y confiables donde las os puedan ejercer su actividad económica dentro de los parámetros que establezca la ley. 

de Santander Colombia

\section{El sector de la Economía Solidaria, eje transformador del tejido social.}

En coherencia con lo anterior, se hizo hincapié en lo que respecta al mapeamiento de las os, pero es pertinente conocer cómo define Coraggio (2009) la economía social y solidaria: "el sistema de instituciones, valores y prácticas que se da en una sociedad para definir, movilizar, distribuir y organizar capacidades y recursos a fin de resolver de la mejor manera posible las necesidades y deseos legítimos de todos sus miembros (reproducción ampliada de la vida de todas y todos, e intergeneracionalmente" (p. 16).

En relación con lo anterior y sumado al propósito del estudio, se hizo necesario aclarar que las empresas sociales y solidarias o las os en sus diferentes tipos, forman parte del sector de la economía solidaria. Por esto, se cita el trabajo de Coraggio (2009) con el ánimo de conocer lo que se plantea conceptualmente sobre economía desde la parte solidaria y social, que es un elemento que enriquece la literatura y que, asimismo, permite contrastar con la realidad que viven las os y su impacto social en los territorios que componen la provincia de Guanentá

De igual manera, las empresas que pertenecen al tercer sector, cuentan con unas características que las hacen particulares y que muestran sus objetivos solidarios frente al desarrollo del tejido social de las diferentes comunidades inmersas en un territorio. Éstas son:

1. En las empresas solidarias el factor organizador no es el capital, sino el trabajo colectivo y el capital social.

2. En las empresas solidarias el capital queda subsumido a la lógica del trabajo y el factor capital económico y social.

3. En las empresas solidarias no se buscan las ganancias con racionalidad maximizadora.

4. Los beneficios de las empresas solidarias incluyen aspectos de rentabilidad económica, pero lo superan integrando el concepto de satisfacción de una pluralidad de necesidades humanas.

5. Dentro de esa definición amplia, caben diversos esquemas de análisis del sistema económico. A continuación, se mencionan algunos de ellos:

- Economía mixta (sistema económico mixto): es el conjunto de recursos, capacidades e instituciones con que cuenta la sociedad para organizar, a través de actividades más o menos interrelacionadas o más o menos segmentadas, el proceso de producción, distribución, circulación, financiamiento y consumo, realizado en y desde un 
territorio determinado, articulando diversas formas de organización: pública estatal o empresarial, privada empresarial y popular, así como sus posibles formas combinadas, a fin de resolver, de manera más o menos justa, la provisión de medios materiales para la atención de las necesidades y deseos de sus miembros.

- El sector de economía popular: abarca las unidades domésticas (hogares o comunidades) y sus extensiones (asociaciones, mutuales y cooperativas, redes de cooperación, representaciones, etc.), orientadas por la reproducción de las vidas de sus miembros, grupos y comunidades particulares en las mejores condiciones a su alcance y con criterios que pauta su cultura.

- El sector de economía empresarial capitalista: las empresas orientadas por la acumulación (crecimiento y reinversión) privada del capital de sus propietarios y sus organizaciones de representación, con una lógica intrínseca extractivista con respecto a la naturaleza, y explotadora con respecto al trabajo ajeno.

En este momento del análisis, no se supone que las organizaciones populares asumen responsabilidad por la vida de miembros de otras organizaciones similares. Si hay solidaridad es interna a la organización, no externa. Armando de Melo Lisboa (2007) citado por Coraggio (2009) Ilama a este segundo tipo solidaridad "ad extra".

El concepto de "capital" se refiere al dinero y otras formas materiales de riqueza que son invertidos para obtener un porcentaje de ganancia máxima medida por referencia al valor del capital. Los emprendimientos populares pueden tener ahorros, una vivienda, utensilios, herramientas, animales, tierra o máquinas utilizados para su reproducción, muchas veces al borde la sobrevivencia, y no para ganar sin límite, esos recursos no deben ser confundidos.

Por otra parte, las cooperativas como os puestas a competir por su supervivencia en el mercado "actúa positivamente, motivada por el egoísmo particular no ya de ganar sin límite, pero sí de asegurar la mejora calidad de vida para sus miembros" (Coraggio, 2000, p. 19). Es por esto que las cooperativas son empresas económicas, al igual que las de las sociedades anónimas, sin embargo, en las sociedades anónimas el poder de decisión, la autoridad, está en manos de aquellos que poseen la mayor porción del capital, mientras que en las cooperativas son todos los miembros las que deciden (Coraggio, 2000).

Las organizaciones de la economía social pueden ser denominadas "empresas" pero no son empresas capitalistas "con rostro social o humano". Su lógica es 
otra: "contribuir a asegurar la reproducción con calidad creciente de la vida de sus miembros y sus comunidades de pertinencia o por extensión de toda la humanidad" (Coraggio, 2011, p. 9). La característica principal que hace diferente al sector solidario en relación con los otros sectores, es el estar "configurado por aquellas expresiones organizadas empresarialmente que siendo en su origen de carácter privado, nacidas de la autonomía, ejercen su misión en temas que son de interés público y/o de carácter social, operando al mismo tiempo fuera de las lógicas mercantiles o del ánimo de lucro individual y fuera de las lógicas burocráticas del Estado" (Coraggio, 2000, p. 22).

De igual manera, la economía social y solidaria es un sistema socioeconómico, cultural y ambiental conformado por el conjunto de fuerzas sociales organizadas en formas asociativas, identificadas por prácticas autogestionarias solidarias, democráticas y humanistas, sin ánimo de lucro, para el desarrollo integral del ser humano como sujeto, actor y fin de la economía (Alcaldía de Bogotá, 1998).

En este sentido, las características de las empresas de economía solidaria, estarían dadas por: estar organizadas como empresa, cuyo objeto social sea satisfacer necesidades de los asociados y el beneficio comunitario, tener establecido un vínculo asociativo, estar incluido en sus estatutos la ausencia de ánimo de lucro, garantizar la igualdad de derechos y obligaciones de sus miembros sin consideración de sus aportes, establecer en sus estatutos un monto mínimo de aportes sociales no reducibles e integrarse social y económicamente con otras entidades sin ánimo de lucro (Monsalve, 2007).

En resumen, el sector de la economía solidaria es amplio y su accionar está dado a través de los diferentes tipos de organizaciones sociales y solidarias, cuyas empresas son las dinamizadoras del desarrollo sustentable de las diferentes colectividades presentes en los territorios, orientadas a la transformación y fortalecimiento del tejido social.

\section{Experiencias significativas o altamente exitosas.}

Las experiencias significativas cobran importancia en un territorio, toda vez que su accionar ayuda a transformar de manera sustentable la calidad de vida de las comunidades. Por eso, se hace relevante "recopilar y organizar información sobre las mejores prácticas; encontrar y compartir las mejores ideas, incluido en áreas como edad y equilibrio entre sexos; identificar las tendencias negativas o perjudiciales, ayudando a describir las malas prácticas y creando instrumentos o técnicas para mejorarlas" (ACl, 2013). Lo anterior define que las buenas y malas prácticas de los emprendimientos solidarios, deben ser socializadas y expuestas ante las demás organizaciones, con el fin de replicar aquellas buenas prácticas en otras comunidades 
$y$, en segundo lugar, poder determinar las falencias o debilidades realizadas en las malas prácticas de tal manera que otras organizaciones no desarrollen o procedan con los mismos errores. Uno de los objetivos de la investigación fue identificar cuáles experiencias significativas se encontraban en la provincia de Guanentá y reconocer cuáles eran las buenas prácticas solidarias que realizan las organizaciones sociales. Se identificaron asociaciones, cooperativas y corporaciones que han sido creadas por la acción católica, otras que han sido creadas de manera espontánea por las mismas comunidades y en otras sobresale el liderazgo de las mujeres en su creación y dirección. Algunas de las buenas prácticas identificadas fueron la vivencia de los principios y valores cooperativos a través de las acciones sociales desarrolladas, generando un impacto de carácter social, económico, ambiental y político en las comunidades en que hacen presencia. Dentro de las malas prácticas se identificó que hace falta que las organizaciones se vinculen en redes para que puedan generar acciones que coadyuven al desarrollo y sostenimiento de las mismas y que puedan generar bienestar y desarrollo a las comunidades de la región.

\section{La provincia de Guanentá, reconocido como territorio solidario.}

La provincia de Guanentá ubicada en el Departamento de Santander, posee una serie de características particulares y cuenta con un sinnúmero de Organizaciones Solidarias. A continuación se muestran estos elementos.

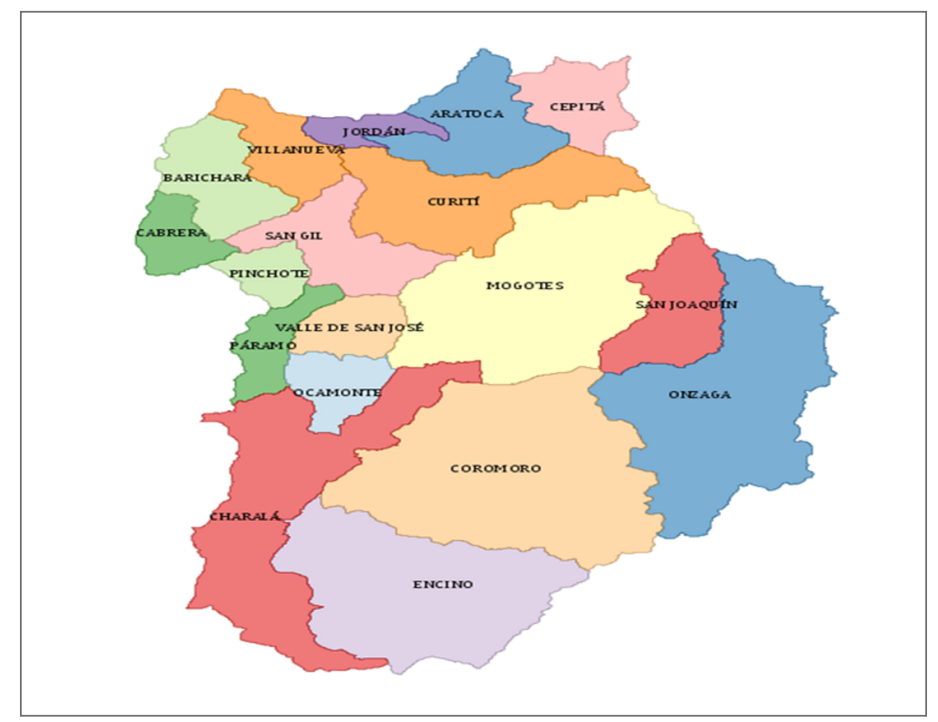

Figura 1. Provincia de Guanentá.

Fuente: (Santander Competitivo Org., 2010) 
En lo referente a la población, según el Departamento Administrativo Nacional de Estadística (DANE) (2019), la provincia de Guanentá cuenta con 141.432 habitantes y tiene una extensión de $3.842 \mathrm{~m}^{2}$. Los principales sistemas productivos de la región son los siguientes: turismo, industria, comercio, tabaco, caña panelera, café, fique, artesanías, minería, servicios públicos y comerciales. De igual manera, cuenta con tesoros históricos, ambientales y culturales que poco a poco se han convertido en el territorio más turístico del departamento de Santander. Asimismo, se identifican, por sus ancestros comuneros, su economía solidaria y sus atractivos turísticos. Por eso, este es un escenario propicio para construir diferentes rutas turísticas focalizadas hacia los procesos de economía solidaria. De hecho, se podrían establecer varias rutas solidarias en concordancia con los intereses de los visitantes.

Según Fajardo (2011) la provincia de Guanentá cuenta con 82 cooperativas y 86 de otros tipos de Organizaciones Solidarias, lo cual, evidencia una alta motivación por parte de las colectividades y los líderes de contribuir con la trasformación y el desarrollo regional. Asimismo, según datos de la Cámara Comercio Seccional San Gil, 2016, en la provincia de Guanentá existen 566 organizaciones solidarias, cifras que revelan la cantidad de empresas de economía solidaria que hacen presencia en la región y que han propiciado desarrollo y crecimiento en las diferentes comunidades locales. Como podemos apreciar, el número de os ha aumentado significativamente en los últimos años.

En resumen, la economía solidaria ha evolucionado durante más de 40 años, a tal grado, que el mundo ve al departamento de Santander y, especialmente, a la provincia de Guanentá, como un escenario del Modelo Cooperativista definido y basado en los principios solidarios. Cabe decir que falta mucho por hacer, pero que el camino está cimentado y, por ello, se debe trabajar de manera conjunta entre todas las organizaciones solidarias, el Estado y las instituciones privadas para poder fortalecer más las empresas de economía solidaria y el impacto social que ellas traen consigo. De igual manera, las tendencias organizativas empresariales en la provincia son favorables desde el punto de vista de la correlación observada en los planes de desarrollo de los Municipios de la Provincia objeto del análisis, del departamento y de la nación, pues en cada plan de desarrollo manifiestan el apoyo a la generación de empleo productivo a través de diversas formas asociativas, esto permite el cumplimiento del principio de coordinación establecido en la ley 152 de 1994. 


\section{Resultados}

\section{Análisis}

En el siguiente apartado se mencionan los hallazgos encontrados, basados en los objetivos propuestos y enfocados a la caracterización de las diferentes os presentes en la provincia de Guanentá. Según la base de datos de la Cámara de Comercio, seccional San Gil, en la provincia de Guanentá se encuentran registradas 566 os, de las cuales se logró recolectar información de 399. Con las 167 os restantes no se pudo establecer contacto por ningún medio, ni con el gerente ni con un encargado y muchas de ellas no estaban en funcionamiento, por lo anterior, se tomó como analisis del 100\% a las 399 os. Se presentan los resultados y análisis referente a: datos y características principales de las os, caracterización de los integrantes, ingresos y condiciones de trabajo y caracterización de los ámbitos de gestión y participación.

\section{Datos generales y características de las Organizaciones Solidarias}

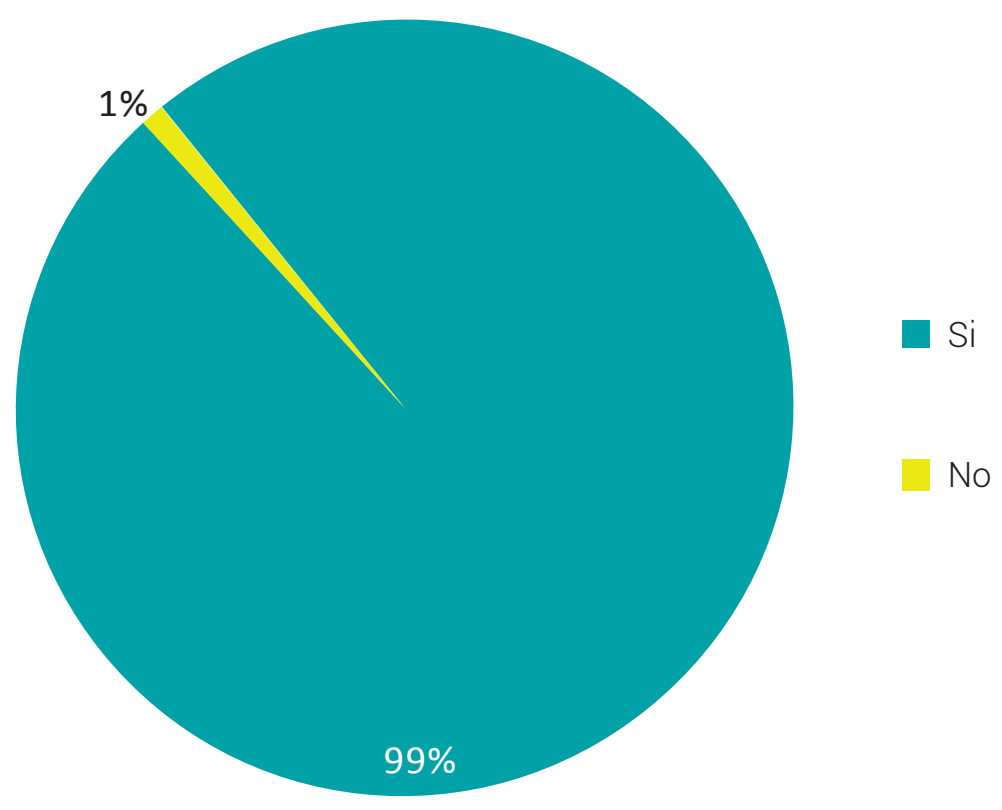

Figura 2. ¿Las os están constituidas jurídicamente? 
El 99\% de los encuestados manifestaron que las os están constituidas jurídicamente, lo que implica que estas organizaciones tienen la identidad y la seriedad que se requiere para hacer negocios encaminados en la producción y comercialización de productos, o en la prestación de servicios; además, refleja el cumplimiento de sus obligaciones y confianza hacia sus asociados y no asociados.

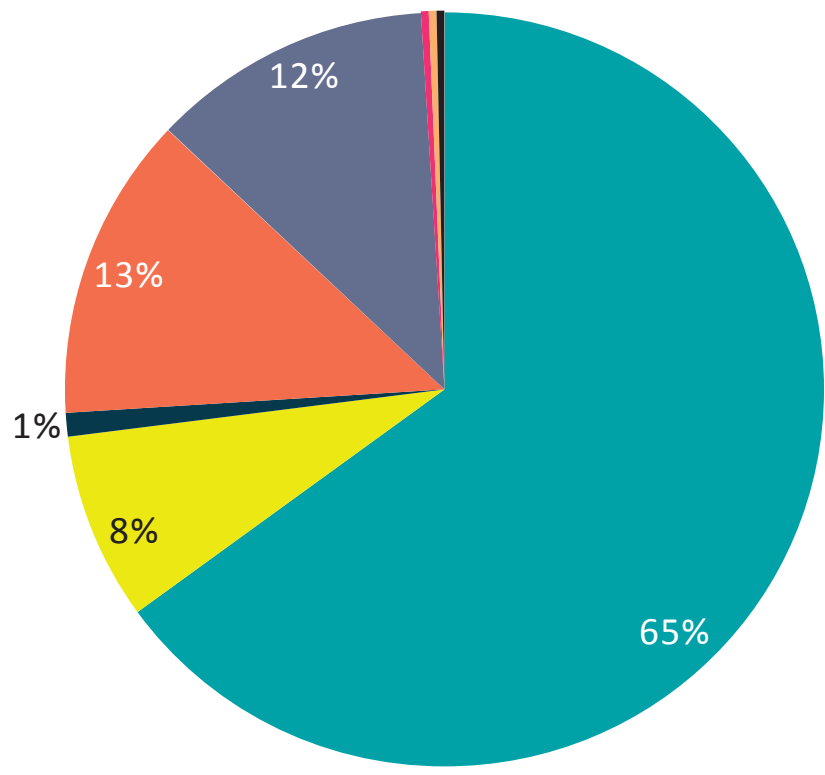

Asociación

Cooperativa

Mutual

Fondo de Empleados

Pre Cooperativas

Corporaciones

Fundaciones

Voluntarios

Otro ¿Cual?

Sociedad

Figura 3. Forma jurídica de la os.

El $65 \%$ de las os son asociaciones, el $13 \%$ son corporaciones y el $12 \%$ fundaciones. De lo anterior, se puede comentar que los encargados o líderes de estas organizaciones optan más por la creación de asociaciones, debido a sus siguientes características: son de libre adhesión, sin número mínimo o máximo de afiliados, sin ánimo de lucro, se consideran Organizaciones Solidarias de Desarrollo (OSD) en la medida en que enfoquen sus acciones y esfuerzos hacia afuera, más que hacia adentro, y se regulan plenamente por sus estatutos, asimismo, su tramitología es mucho más sencilla en comparación con los demás tipos de os, y además, los costos para su constitución son más económicos. 


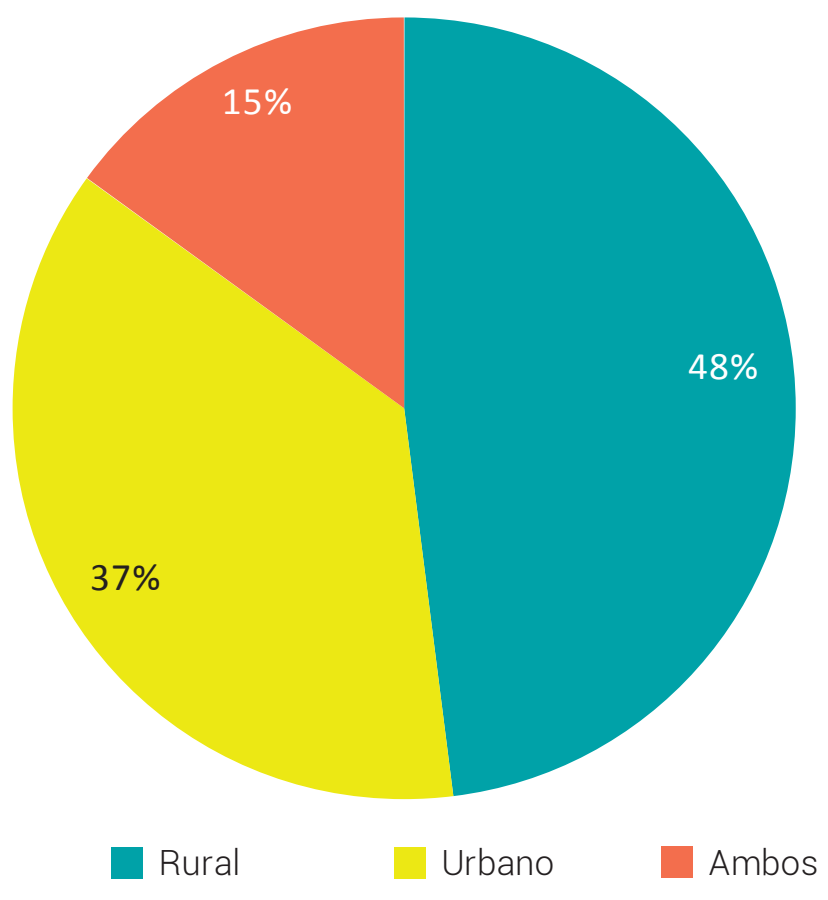

Figura 4. Ámbito sociodemográfico donde se ubica el emprendimiento solidario.

Según los encuestados, el 48\% de las os están ubicadas en el sector rural, un $37 \%$ en el casco urbano y un $15 \%$ en ambos lugares. Lo anterior implica que, en su mayoría, las os solidarias están ubicadas geográficamente en el sector rural debido a que allí, en primer lugar, se encuentra concentrada la mayor parte de la población de los municipios; en segundo lugar, esta ubicación les permite a los asociados e integrantes de la organización una cercanía para realizar las actividades propias de la empresa, manejar estrategias mucho más eficaces en el desarrollo de los procesos productivos y en la prestación de los servicios y, finalmente, en la mayor parte de los municipios de la provincia de Guanentá desarrollan actividades agropecuarias, lo cual obliga a las os ubicarse en este sector. 


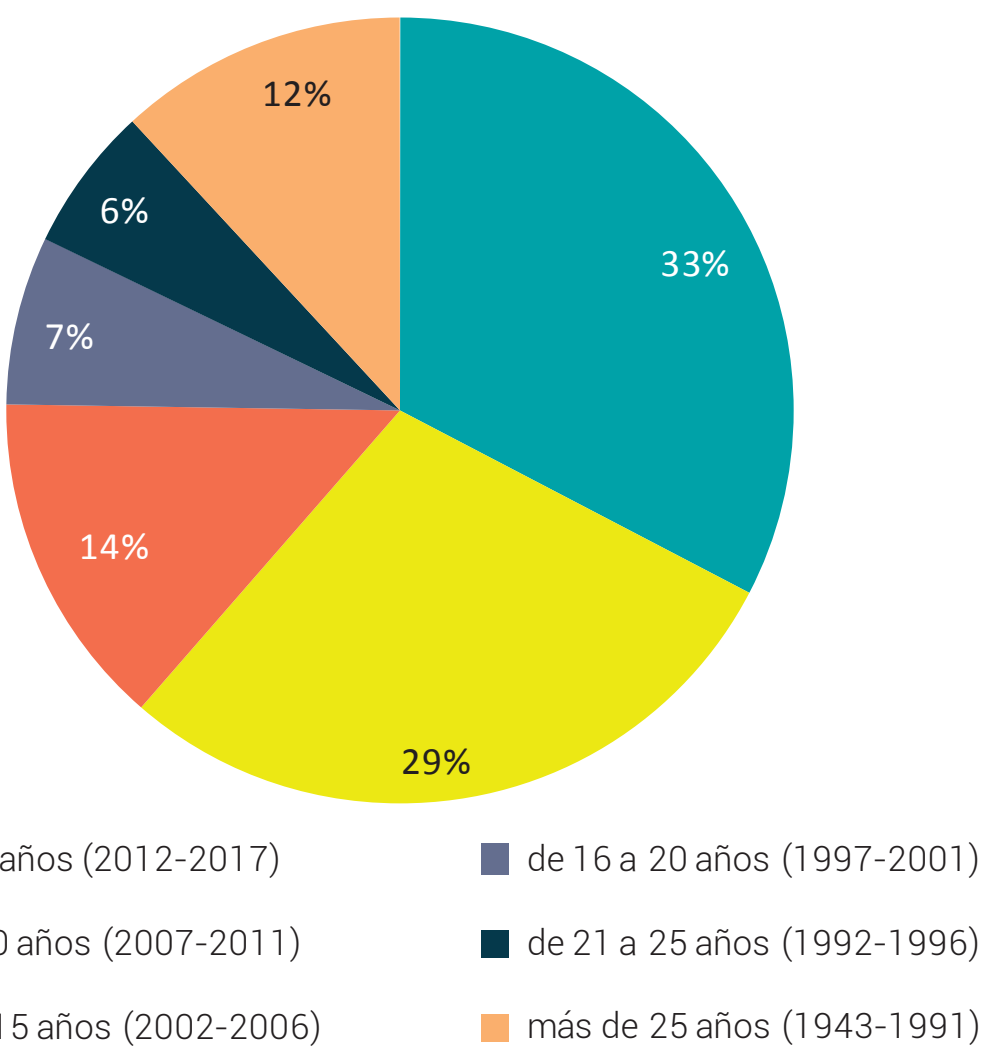

Figura 5. Años de funcionamiento de las os

Dentro de los datos más representativos se tienen: el $62 \%$ de las os llevan funcionando de 1 a 10 años; el 21\% de 11 a 20 años, lo que indica que las organizaciones han podido mantenerse a lo largo del tiempo, a pesar de los grandes cambios surgidos en el contexto en que tienen su accionar, además, se puede inferir el liderazgo y la buena gestión empresarial asumido por los diferentes administradores, representantes legales o gerentes de las entidades, quienes han podido, de una u otra manera, superar los percances que se han presentado diariamente dentro sus procesos y procedimientos empresariales. 


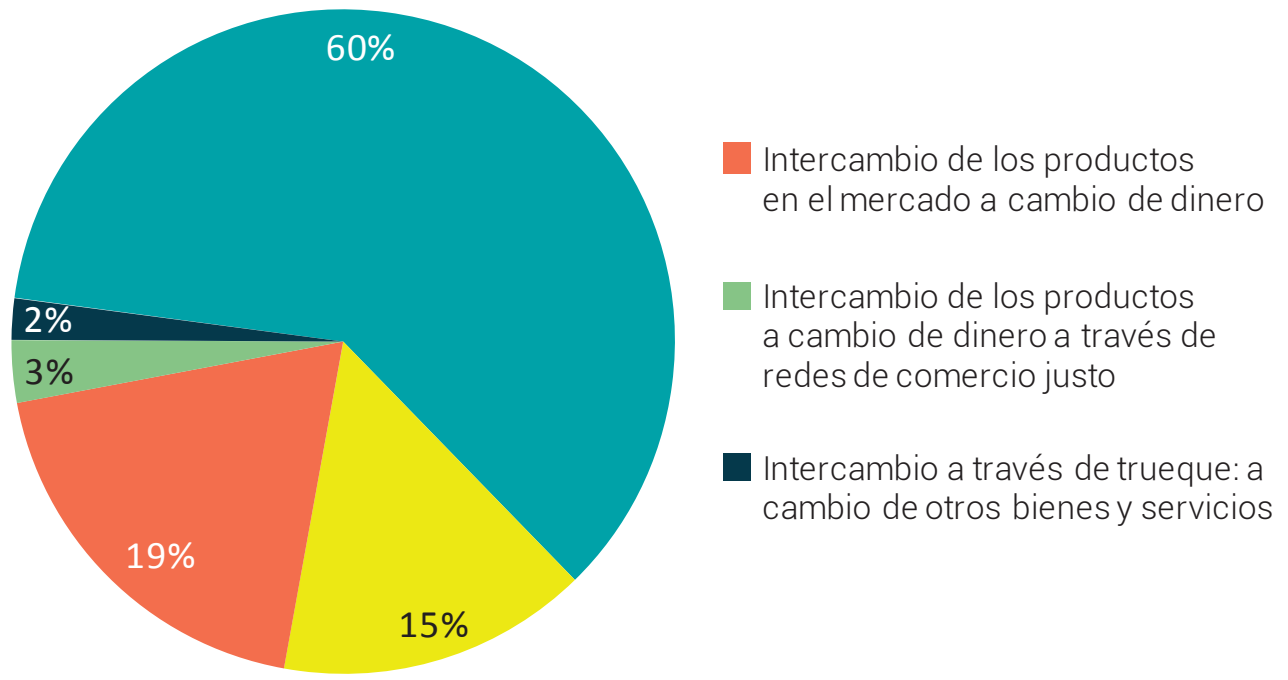

Figura 6. Productos o servicios de las os.

El 60\% de las os, producen bienes y servicios para su autoconsumo, es decir, producen para el consumo de sus propios asociados, teniendo en cuenta sus necesidades; el 19\% elaboran los productos o servicios con el fin de realizar un intercambio en el mercado a cambio de dinero, lo que es lógico, pues es necesario recibir una contraprestación por los servicios o productos brindados.

\section{Características de los Integrantes de las Organizaciones Solidarias.}

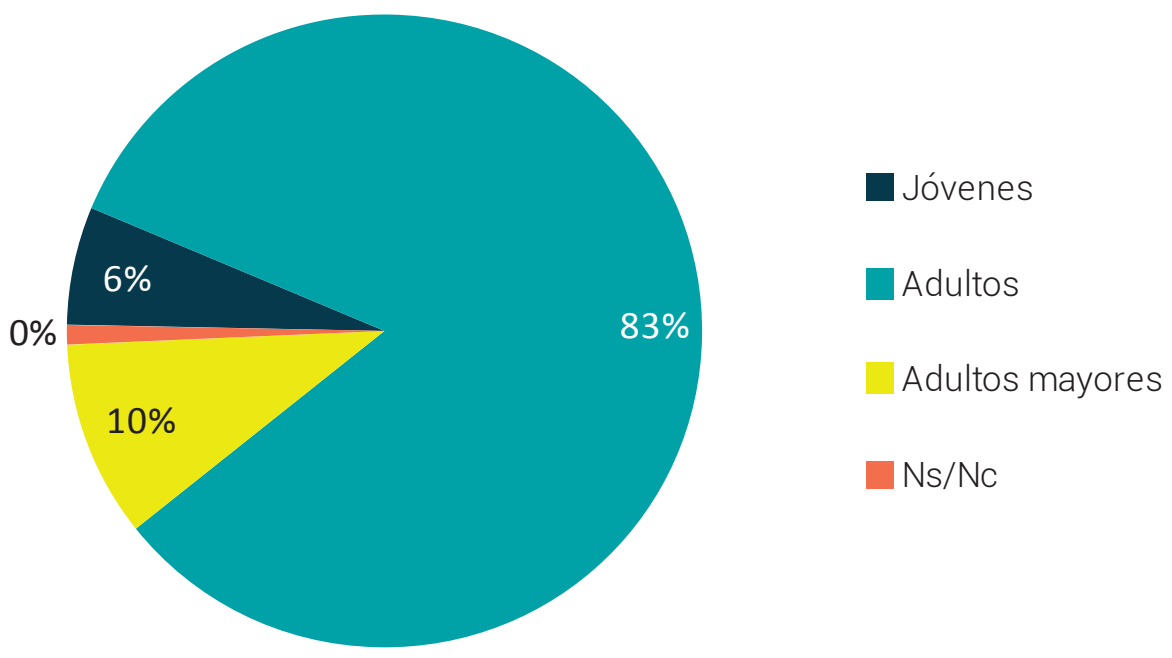

Figura 7. Edad predominante de los miembros del emprendimiento solidario. 
El 83\% de los encuestados expresaron que la edad predominante en las os son los adultos, ellos consideran a la organización como su obra de arte, son personas orientadas al logro, tienen mucha confianza en sí mismos y en los demás y son líderes comprometidos en sus comunidades que buscan siempre el bienestar común; el 10\% dijeron que la edad predominante son adultos mayores y, por último, el 6\% manifestaron que son los jóvenes, dato muy preocupante, ya que ellos se suponen que van a ser los futuros líderes de las organizaciones sociales inmersas en la región.

Tabla 1. Cantidad de personas que integran las os.

\begin{tabular}{ccccccc}
\hline $\begin{array}{c}\text { Personas que } \\
\text { la Integran }\end{array}$ & Asociados & $\begin{array}{c}\text { Trabajadores } \\
\text { Contratados }\end{array}$ & $\begin{array}{c}\text { Ayudantes no } \\
\text { remunerados. }\end{array}$ & Otros & Hombres & Mujeres \\
\hline $\mathbf{2 8 3 . 8 8 6}$ & $\mathbf{2 3 2 . 0 9 6}$ & 1.317 & 3.984 & 489 & 120.940 & 162.946 \\
\hline
\end{tabular}

Las os están integradas por 283.886 personas naturales, de las cuales 232.096 son asociados, 1.317 son trabajadores contratados, 3.984 ayudantes no remunerados y 489 están dentro de la categoría de otros, es decir, son aquellas personas que, en algunas ocasiones, reciben pago por prestar un servicio o a veces no lo reciben, sino que les dan un beneficio de manera colectiva, como por ejemplo, en las asociaciones de acueductos veredales, el beneficio recibido es el agua tratada y lista para el consumo humano. Por otro lado, se observa que la cantidad de hombres que conforman las os es de 120.940 y de mujeres es de 162.946, cifras que muestran el aumento de la participación de las mujeres en los emprendimientos sociales.

\section{Ingresos y condiciones de trabajo.}

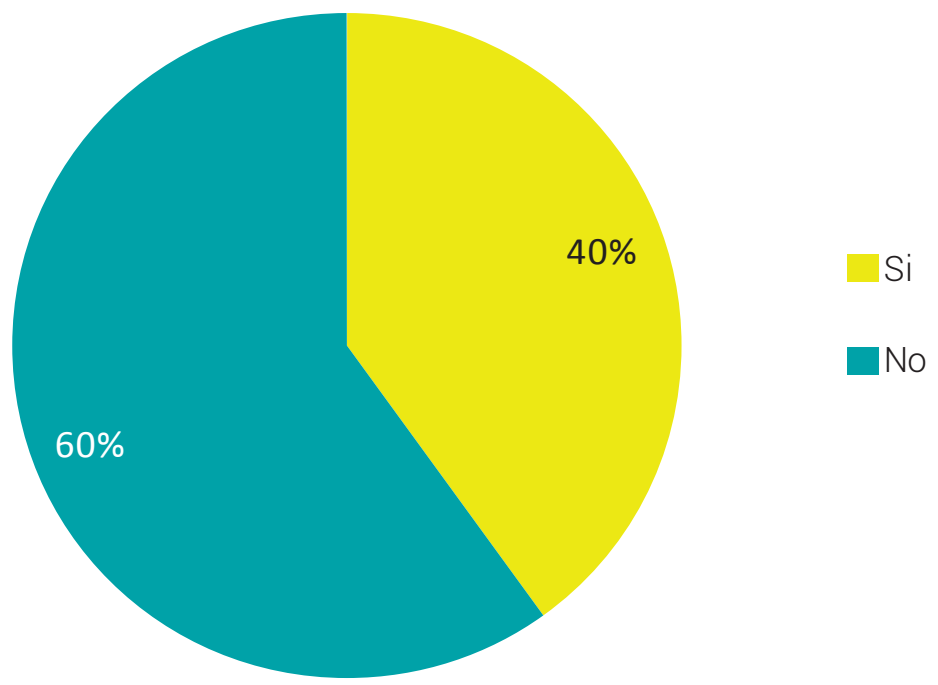

Figura 8. Los miembros/asociados reciben ingreso. 
El 40\% de los encuestados manifestaron que sí reciben ingresos por su actividad, especialmente, en dinero; mientras que el 60\% manifiesta que no reciben ingresos, pero en retribución reciben beneficios, como por ejemplo en los acueductos veredales, el beneficio es recibir el agua en óptimas condiciones, lo cual, mejora la calidad de vida de las comunidades.

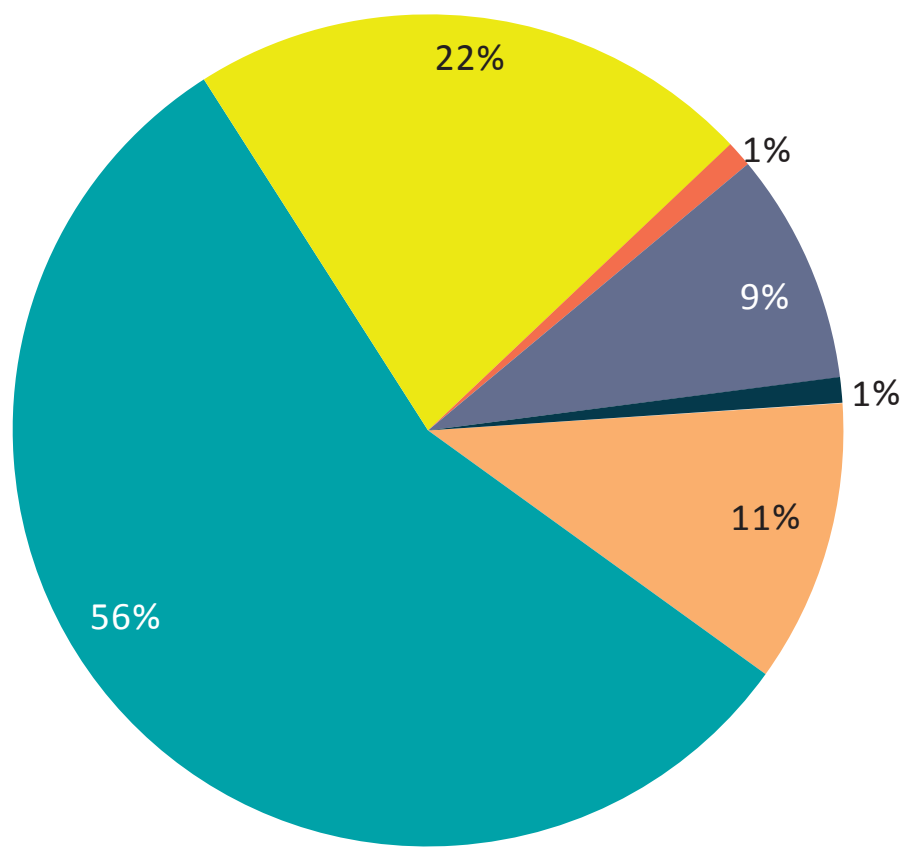

Suma fija igual para todos los asociados

- Suma diferencial por cargo, función, actividad, etc.

- Porcentaje o proporción sobre las ventas, las horas trabajadas, la producción realizada, etc...

- Según las necesidades de cada integrante ok

- $\mathrm{Ns} / \mathrm{Nc}$

Figura 9. Remuneraciones de los trabajadores.

El 56\% manifestaron que la remuneración de los trabajadores se establece con suma diferencial por cargo, es decir, la escala salarial se ha establecido acorde o en concordancia con el cargo desempeñado en la os, lo que lo hace más justo y equitativo, ya que, entre mayor sea el cargo en la empresa, mayor son las responsabilidades; un 22\% de las os coincidieron en que la remuneración de los trabajadores es por porcentaje sobre las ventas, las horas trabajadas o la producción realizada, esto implica que el pago se hace en relación a la obra o labor realizada. 


\section{Características generales de los ámbitos de gestión y participación.}

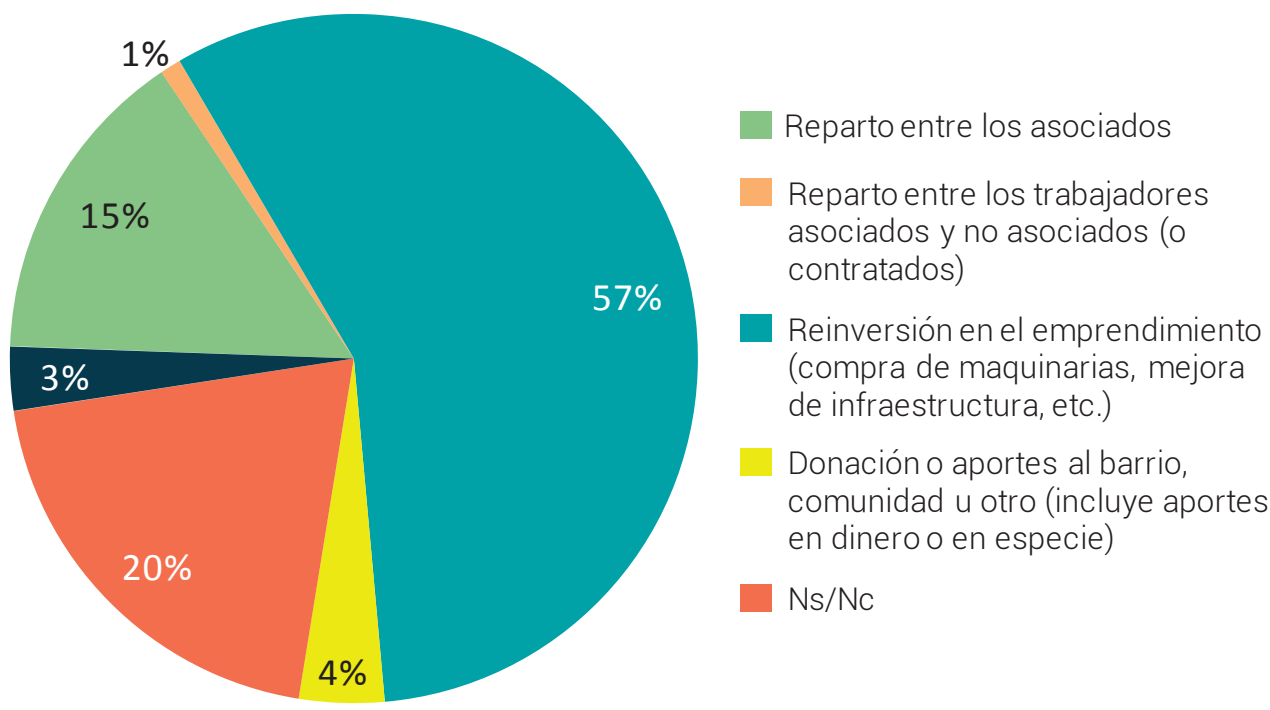

Figura 10. Destinos de los excedentes.

Si el emprendimiento solidario llegara a tener excedentes, un 57\% haría una reinversión en el emprendimiento, ya que en muchas entidades dependen de ello para su subsistencia; mientras que el 15\% haría un reparto entre los asociados.

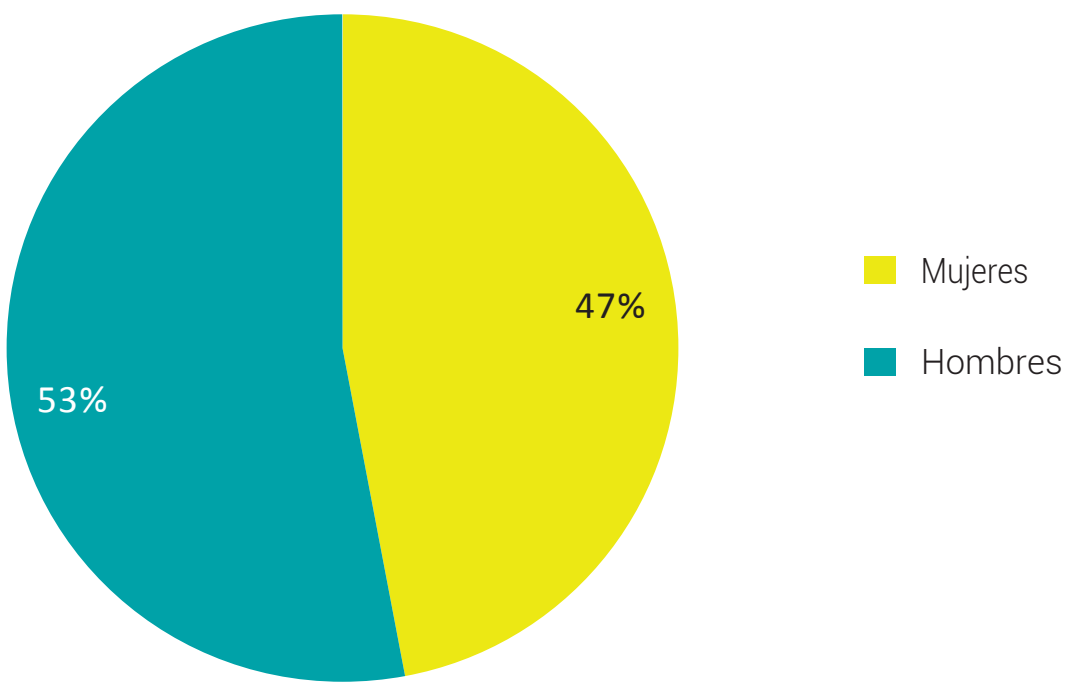

Figura 11. Hombres y mujeres que se encargan de la coordinación o direccionamiento general del Emprendimiento Solidario. 
El 53\% de las personas que se encargan de la coordinación o direccionamiento general de los emprendimientos solidarios son hombres y un $47 \%$ son mujeres, esto permite deducir que hay un porcentaje relativamente similar de hombres y mujeres que lideran las os, pero lo más significativo es ver como que el rol de la mujer en el liderazgo tanto en las empresas como en otros escenarios, ha venido tomando fuerza en los últimos años.

\section{Conclusiones}

\section{Características de las Organizaciones Solidarias y sus integrantes}

Con base en las principales características que definen a las os establecidas en la Ley 454 de 1998, como por ejemplo: ejercer una actividad socioeconómica que busque satisfacer las necesidades de sus asociados, ser una organización sin ánimo de lucro y que realice acciones orientadas a la solidaridad, de servicio comunitario o social, entre otras. En cuanto al primer enunciado y en contraste con el presente informe, se observó que las os presentes en la provincia de Guanentá (399), son un fiel ejemplo de asociatividad que busca, en primera instancia, satisfacer las necesidades de sus asociados y también la de sus familias. En segundo lugar, y relacionado con la concepción de que las os realizan acciones orientadas a la solidaridad, de servicio comunitario o social, esto es un hecho tangible, ya que los diferentes tipos de organizaciones presentes en el territorio muestran a través del trabajo realizado por sus líderes, que la labor colectiva, la ayuda mutua, la colaboración, el trabajo cooperativo, la práctica de los principios solidarios, han construido un territorio más solidario y participativo, mejorando por muchos años las condiciones de vida de las diferentes colectividades presentes en la región.

Coraggio (2009) define la Economía Solidaria como

el sistema de instituciones, valores y prácticas que se da en una sociedad para definir, movilizar, distribuir y organizar capacidades y recursos a fin de resolver de la mejor manera posible las necesidades y deseos legítimos de todos sus miembros (reproducción ampliada de la vida de todas y todos, e intergeneracionalmente). (p. 8)

Con base en esta definición, se aprecia que las os que están en la provincia de Guanentá, han propiciado un escenario en que las comunidades han podido 
transformar mental y socialmente su forma de organizarse y, de esta manera, han podido construir de manera colectiva y no individual su propio desarrollo, pensando siempre en mejorar su calidad de vida.

Se observa la necesidad de

fortalecer los sistema de registro y ampliar la base de datos de información sobre el sector solidario y en particular sobre las Organizaciones Solidarias de Desarrollo, teniendo en cuenta que la información es vital para conocer su situación, contribuir en su acción social y definir políticas públicas precisas y evaluables donde se asuma la sociedad civil como un actor político y social relevante. (Vivas, González y Gómez, 2015, p. 8)

Lo anterior invita a poner en marcha el fortalecimiento de las os en cuanto a la creación de una base de datos más real y con datos actualizados, que permita la posibilidad de una mayor articulación e interacción, generar mayor visibilidad de dichas entidades y la definición de políticas públicas relacionadas con ellas y, para ello, el presente estudio da un gran aporte al momento de identificar, clasificar y caracterizar cada una de las empresas del tercer sector inmersas en el territorio, teniendo en cuenta el sentido de pertenencia, la práctica de los principios solidarios, la autogestión, la Intercooperación, entre otros aspectos, que hacen parte del desarrollo diario y continuo de las diferentes instituciones.

Se destaca que el 99\% de las os están constituidas jurídicamente, generando mayor identidad, visibilidad, confianza, seriedad, a la hora de realizar negocios encaminados a la producción y comercialización de productos y prestación de servicios; además, refleja cumplimiento de sus obligaciones y confianza hacia todos sus asociados y no asociados. La forma jurídica más utilizada en la conformación de las os son las asociaciones (65\%), debido a la facilidad en su tramitología y, en particular, por los siguientes aspectos: son de libre adhesión, sin número mínimo o máximo de afiliados, sin ánimo de lucro, se consideran OSD en la medida en que enfoquen sus acciones y esfuerzos hacia afuera, más que hacia adentro y se regulan plenamente por sus estatutos, además, los costos para su constitución son más económicos.

El 48\% de las os están ubicadas en el sector rural y un 37\% en el casco urbano, es decir, un número significativo de estas están ubicadas en el sector rural, debido a que allí es donde en primer lugar, se encuentra concentrada la mayor parte de la población de los municipios que integran la provincia de Guanentá y, en segundo lugar, esta ubicación les permite a los asociados e integrantes de las os una cercanía para realizar las actividades propias de la empresa. 
El 62\% de las os llevan funcionando de 1 a 10 años, el 21\% de las entidades de 11 a 20 años; lo que indica que estas han podido mantenerse a lo largo del tiempo, a pesar de las grandes transformaciones surgidas en el contexto en que tienen su accionar, evidenciando el liderazgo, la pujanza, la perseverancia y el sentido de pertenencia de los gerentes o administradores de las os y, de igual manera, la de los asociados.

El 60\% de las os producen bienes y servicios para su autoconsumo, es decir, la producción de bienes o servicios se utiliza para satisfacer las necesidades de las personas que conforman las os. La edad predominante de los miembros en las os en un $83 \%$ es de adultos, que oscilan entre los 25 y 60 años, edad propicia que genera un grado de seguridad y confianza en la toma de decisiones en las os. Por otro lado, el $6 \%$ de las os están conformadas por los jóvenes, dato muy preocupante, ya que ellos se suponen que van a ser el relevo generacional y los futuros líderes de las organizaciones sociales inmersas en la región.

Las Empresas de Economía Solidaria están conformadas por 283.886 personas naturales, de las cuales 232.096 son socios, 1.317 son trabajadores contratados, 3.984 ayudantes no remunerados y 489 están dentro de la categoría de otros, es decir, son aquellas personas que, en algunas ocasiones, reciben pago por prestar un servicio o a veces no lo reciben, sino que les otorgan un beneficio colectivo como, por ejemplo, en las asociaciones de acueductos veredales, en donde el beneficio recibido es el agua tratada y lista para el consumo humano.

El $47 \%$ de las personas que se encargan de la coordinación o direccionamiento general de los emprendimientos solidarios son mujeres, lo que demuestra el liderazgo que han venido tomando dentro de las os en los últimos años. De igual forma, las mujeres que hacen parte de estas entidades son luchadoras, emprendedoras, con un gran sentido de pertenencia, con sentido social y con grandes destrezas para la toma de decisiones.

\section{Mapeamiento de los os de la provincia de Guanentá}

Se tomó el instrumento o guía elaborada por Coraggio como modelo, con el cual se recolectó información de cada una de las os activas presentes en la provincia de Guanentá; dicha información permitió tener una actualización real de los datos y las características de las 399 os en un ámbito geográfico.

Así, el mapeamiento y relevamiento de las organizaciones solidarias contribuye a su fortalecimiento y articulación en los ámbitos regional, departamental, nacional e internacional; por otra parte, favorece la visibilidad de las oEs así como también la formulación y aplicación de políticas públicas y la elaboración del marco jurídico, 
que posibilite a dichas entidades tener unas normas y leyes enmarcadas dentro de la jurisprudencia del gobierno nacional y, a partir de allí poder tener unas bases sólidas y confiables en que las os puedan ejercer su actividad económica dentro de los parámetros establecidos por la ley.

\section{Experiencias significativas}

Las experiencias significativas de organizaciones de economía solidaria que fueron investigadas en la provincia de Guanentá presentan orígenes, trayectorias y desarrollos diversos. Sin embargo, todas ellas han tenido momentos de crisis y de cambio. A continuación, se presentará un análisis de su origen, productos y servicios, gobernabilidad, redes y alianzas, principales fortalezas, retos (desafíos) y los aportes que realizan al territorio, se unificarán teniendo en cuenta su objeto social: asociaciones (acueductos rurales, madres cabezas de hogar, jóvenes), Cooperativa Comulseb, Corporación Corpolienzo y la Fundación reserva moral.

Origen de las os: un primer aprendizaje que se puede obtener de las experiencias investigadas es la de constatar, en todos los casos la existencia de un núcleo inicial impulsor, que se mantiene básicamente a lo largo del tiempo, con unas características propias y diferenciadas de otras iniciativas de carácter empresarial. Se destacan las relaciones de confianza, la participación, la gerencia responsable, la prestación eficiente de servicios, la solidaridad, entre otros aspectos que han mejorado la calidad de vida y las necesidades de un territorio, siempre desde la búsqueda del interés social. Este colectivo de organizaciones se divide en cuatro grupos:

a) Algunas organizaciones solidarias de la provincia de Guanentá, fueron creadas por la acción de la I glesia católica, la cual promovió la organización de sindicatos agrarios en el territorio diocesano. Había una cierta inactividad de los sindicatos y otras necesidades como el crédito, la comercialización y la educación, que no estaban teniendo respuestas adecuadas. Caso de la cooperativa de (COOMULSEB).

b) En el caso de los acueductos rurales, fueron constituidos de manera espontánea y, de hecho, por las comunidades campesinas (acueducto el HOBO, las alegrías), de igual manera, una vez establecida la ley de protección del agua, El Secretariado Diocesano de Pastoral Social (SEPAS), consideró conveniente impulsar la constitución jurídica de los acueductos rurales en el territorio diocesano. De esta manera, actualmente, cuenta con 155 acueductos y un proceso de estructuración de una red territorial de 
acueductos comunitarios rurales. La pastoral social impulsa estos acueductos a partir de tres postulados básicos: el agua es un don de Dios, el agua es un derecho, el agua es para todos.

c) Las asociaciones de mujeres, fueron constituidas por mujeres líderes que vieron la necesidad de empezar a crear sus propios ingresos económicos, a través de la asociación, encaminados en la búsqueda de un proyecto viable que posibilitará el beneficio colectivo de las mismas.

d) A través de los líderes sociales surgió la corporación para la recuperación comunera del Lienzo como una iniciativa de las mujeres de las empresas comunitarias en pro de recuperación de la cultura ancestral Guane, lo que implicó el cultivo de algodón, hilado y tejido a mano y, por último, la fundación reserva moral, cuya finalidad es brindar acompañamiento psicológico y clínico a personas afectadas por el flagelo de la drogadicción, así como a sus familias.

Productos y servicios: las experiencias significativas de las organizaciones solidarias, en el ámbito de la producción de bienes y servicios se dan como un modelo de subsistencia y mejoramiento de calidad de vida, es así que dentro de las experiencias investigadas, se tienen asociaciones de servicios de agua potable y de calidad, productos agrícolas como la cría y levante de gallina ponedora y de pollos semicriollos, abono orgánico, café pergamino; de igual manera, a la fabricación de artesanías en fique, entre otros; Corpolienzo organización que fabrica productos con algodón orgánico completamente artesanales; Cooperativa de ahorro y crédito Comulseb cuyo servicio es la prestación de ahorro y crédito y, por último, la Fundación reserva moral. Todas estas organizaciones cumplen una finalidad común y es mejorar las condiciones de calidad de vida a los asociados y aportar al fortalecimiento y al desarrollo territorial.

Cada organización ejerce un proceso de gobernanza y liderazgo, por el cual se reúnen de manera periódica con el fin de atender las necesidades de las organizaciones y tomar diferentes tipos de decisiones en pro del mejoramiento de la calidad de vida de los asociados. Dentro de los procesos de participación en redes y alianzas, todas las organizaciones solidarias consideran que trabajar en redes y hacer alianzas es de vital importancia para fortalecer los procesos de las organizaciones; sin embargo, solo algunas de ellas hacen parte de alguna red, entre las cuales se encuentran: las asociaciones de acueducto que pertenecen a la "Red agua para la vida"; Corpolienzo que trabaja conjuntamente con organizaciones como: Agrosolidaria, Administración Municipal, SENA, Cámara de Comercio, UNISANGIL y Artesanías de Colombia. De igual manera, para las que no estén vinculadas a ninguna red, se hace necesario que 
realicen alianzas para que mejoren su gestión y, de esta manera, generen un mayor desarrollo y un crecimiento solidario que gesten mejores dinámicas organizacionales.

Principales fortalezas, retos y desafíos de las organizaciones: el trabajo en asociación los ha llevado a complementarse y, de esta manera, a lograr el reconocimiento en asociatividad, el respeto como personas, como empresa y como familia, la colaboración, el positivismo y la capacidad para desempeñarse en los diferentes procesos relacionados con la producción y comercialización de los productos.

Dentro de las fortalezas se encuentran los valores que se practican en las organizaciones como: la solidaridad, la ética, el servicio, responsabilidad, la ayuda mutua, las vivencias que se han generado en cada una de las organizaciones, la capacidad que han tenido para solucionar los problemas a pesar de las adversidades. Se puede decir que las lecciones de vida que tienen, el ser constante en lo que se hace, el entusiasmo y la búsqueda generar nuevos recursos, dar una mejor calidad de vida a sus familias, enseñar a los jóvenes a vivir el espíritu de la solidaridad y a no olvidar sus raíces y, de esta manera, generar un mejor desarrollo territorial.

Con la creación de estas organizaciones se generaron cambios no solo económicos en las personas que las constituyen, sino también experiencias vividas como la interacción con miembros de su comunidad que, en algunos casos, ni siquiera conocían, la solidaridad, la compresión, ser proactivas al momento de buscar estrategias y soluciones. Todo lo anterior coadyuva a crear y fortalecer beneficios en sus vidas, creando una mente emprendedora con ganas de superarse y salir adelante.

Uno de los desafíos que se proponen a nivel general es ser líderes en la promoción del desarrollo rural a través de procesos agroindustriales de alta tecnología, diseñando productos capaces de conquistar los más exigentes mercados, apoyados en el talento humano altamente calificado que permita mejorar el nivel de vida de los asociados y de la región. Buscan ser modelo para otras familias que se encuentren con situaciones similares, aportando su experiencia como un ejemplo de superación, hacer ver que cuando realmente se quiere, se puede y que, con empuje, dedicación, constancia y esfuerzo los proyectos salen adelante. Aspiran a tener más recursos propios para de esta manera poder encaminar nuevos proyectos rentables y sostenibles y, así, dar ayuda a más familias que lo necesiten. Su visión es seguir manteniendo y mejorando cada día el nivel de vida en las familias, brindar bienestar y seguridad, además de asegurar la adecuada educación de los niños y los jóvenes para ir construyendo el futuro solidario de Colombia. 


\section{Referencias}

ACI (2013). Alianza Cooperativa Internacional. http://www.aciamericas.coop/

Alcaldía de Bogotá (1998). Ley 434 de 1998. http://www.alcaldiabogota.gov.co/sisjur/normas/ Norma1.jsp?i=3433

ASCOOP. (2016). Asociación de Cooperativas de Colombia. https://ascoop.coop/

Cámara de Comercio, seccional San Gil (2016). Base de datos Organizaciones Solidarias.

Coraggio, J. (2011). Economía social y solidaria el trabajo antes que el capital. FLACSO Ecuador. https://www.coraggioeconomia.org/jlc/archivos\%20para\%20descargar/economiasocial. pdf

Coraggio, J. (2000). América Latina: necesidad y posibilidades de otra Economía. Otra Economía, 2, 8-11.

Fajardo, M. (2011). Territorio solidario: provincias del sur de Santander. Unisangil Empresarial, 5(1), 5-19.

LEXICOON (2016). Caracterizar. http://lexicoon.org/es/caracterizar

Monsalve, A. (2007). 100 Claves de la economía solidaria. Editorial Guadalupe.

Mothé, D., Cattani, A. D., Coraggio J. L. y Laville J. L (2009). Diccionario de la otra economía. Clacso Coediciones.

The Free Dictionary (2016). Caracterizar. http://es.thefreedictionary.com/caracterizar

Vivas, O., González, J. y Gómez, J. L. (2015). Caracterización de las diferentes formas de organización social en Colombia: Las Organizaciones Solidarias de Desarrollo (OSD). Revista Científica General José María Córdoba, 13(13), 57-59. 